\title{
Comparative Study of Two Techniques for Ligament Balancing in Total Knee Arthroplasty for Severe Varus Knee: Medial Soft Tissue Release vs. Bony Resection of Proximal Medial Tibia
}

\author{
Ji Hyun Ahn, MD, and Young Woong Back, MD \\ Department of Orthopaedic Surgery, Dongguk University Ilsan Hospital, Goyang, Korea
}

\begin{abstract}
Purpose: Bony resection of the proximal medial tibia, an alternative technique for soft tissue balancing in total knee arthroplasty (TKA), was compared to the conventional medial soft tissue release technique.

Materials and Methods: From June 2005 to June 2007, we performed 40 TKA in 27 patients with $\geq 10^{\circ}$ tibio-femoral varus deformity. The conventional, medial soft tissue release technique was applied in 20 cases and bony resection of proximal medial tibia in the other 20 cases (vertical osteotomy group). Total operation time, knee range of motion (ROM), hospital for special surgery (HSS) scores, and tibio-femoral medial-lateral gap ratio in $0^{\circ}, 90^{\circ}$, and $130^{\circ}$ flexion at postoperative 6 months were compared between the groups.

Results: The total operation time was shorter in the vertical osteotomy group. Tibio-femoral medial-lateral gap ratio in $130^{\circ}$ flexion was closer to 1 in the vertical osteotomy group ( $\mathrm{p}=0.000$ ). There was no significant difference in the ROM, HSS score, or tibio-femoral medial-lateral gap ratio in $0^{\circ}$ and $90^{\circ}$ flexion at postoperative 6 months.

Conclusions: In severe varus knees, bony resection of proximal medial tibia can be considered as an alternative technique, in order to decrease total operation time and to obtain medial-lateral, soft-tissue balance in deep flexion.
\end{abstract}

Keywords: Knee, Varus deformity, Total knee arthroplasty, Bony resection, Proximal medial tibia

\section{Introduction}

Total knee arthroplasty (TKA) has been frequently performed for severe degenerative arthritis in senior patients. Unfortunately, TKA can be technically challenging in knees with profound varus deformity when it is combined with medial soft tissue contracture and lateral soft tissue laxity ${ }^{1)}$. Ligament balancing has

Received May 3, 2011; Revised (1st) September 20, 2011;

(2nd) April 4, 2012; (3rd) October 27, 2012; Accepted October 30, 2012

Correspondence to: Ji Hyun Ahn, MD

Department of Orthopaedic Surgery, Dongguk University Ilsan Hospital, 27 Dongguk-ro, Ilsandong-gu, Goyang 410-773, Korea

Tel: +82-31-961-7317, Fax: +82-31-961-7290

E-mail: drsky71@duih.org

This is an Open Access article distributed under the terms of the Creative Commons Attribution Non-Commercial License (http://creativecommons.org/licenses/by-nc/3.0/) which permits unrestricted non-commercial use, distribution, and reproduction in any medium, provided the original work is properly cited. been considered essential to the success of a TKA ${ }^{2)}$ and release of the contracted medial soft tissues from the tibial attachment site has been widely performed to balance the medial-lateral soft tissue tension ${ }^{1,3,4)}$. However, this technique may result in an intraoperative rupture in the presence of soft tissue contracture or adhesion or medial instability of the knee ${ }^{5-7}$. Minimal soft tissue release followed by resection of the proximal medial tibia along the longitudinal axis of the tibia can be considered as an alternative. This technique is expected to be a safer option that would reduce the incidence of complications, such as medial collateral ligament (MCL) rupture, by allowing minimal release of the superficial layer of the MCL from the tibial attachment site $^{8)}$. In spite of this, there has been no domestic study on this technique.

The purpose of this study was to compare the results of TKA using the conventional medial soft tissue release and longitudinal bony resection of the proximal medial tibia with minimal soft tissue release in severe varus knees. 


\section{Materials and Methods}

Of the patients who underwent TKA performed by the same surgeon at our institution between June 2005 and June 2007, 27 patients (40 cases) with $\geq 10^{\circ}$ tibio-femoral varus deformity on the preoperative whole leg standing anteroposterior (AP) view (Fig. 1) were included in this prospective randomized controlled study. All study participants were female with a mean age of 71.5 years (range, 62 to 83 years). The mean preoperative, anatomical tibio-femoral axis was varus $13.3^{\circ}$ (range, $11^{\circ}$ to $19^{\circ}$ ) (Table 1 ).

TKA was performed using a posterior-stabilized type prosthesis in all cases. For ligament balancing, the conventional medial soft tissue release was performed in 20 cases (medial release group). In the remaining 20 cases (vertical osteotomy group), a vertical osteotomy for one size smaller tibial component was performed using an osteotome in the proximal medial tibia for ligament balancing (Fig. 2).

There was no statistically significant difference in age and preoperative varus deformity angle, range of motion (ROM), and hospital for special surgery (HSS) score between the groups. In the medial release group, the knee joint was exposed using a midvastus approach and medial soft tissue was released up to $1 \mathrm{~cm}$ distally from the subperiosteal layer of the joint capsular insertion site, on the proximal tibia and then posteromedially. Progressive soft tissue release was carried out until symmetrical, medial-lateral balance was confirmed using a trial prosthesis after femoral and tibial articular surface resection. The initial medial release was extended $\geq 1 \mathrm{~cm}$ distally in all of the medial

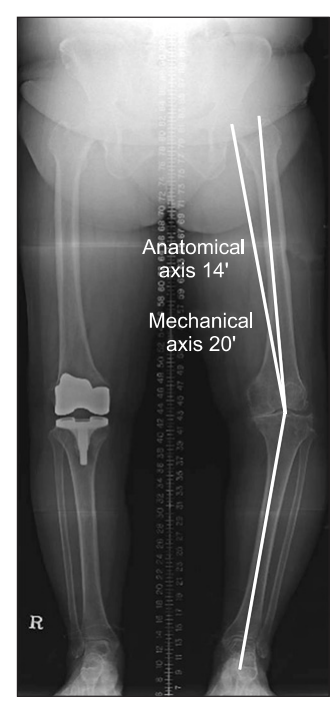

Fig. 1. Anteroposterior radiograph of both knees showing arthritic change of the medial, tibio-femoral joint with severe varus deformity. release group $(n=20)$. Medial-lateral tension was assessed with the knee in extension and $90^{\circ}$ flexion. If medial soft tissue contracture was noted in extension, the deep layer of the MCL and the posteromedial joint capsule were released; whereas the superficial layer of the MCL and the anteromedial joint capsule were released, if contracture was noted in $90^{\circ}$ flexion to obtain a perfect ligament balance.

In the vertical osteotomy group, a midvastus approach was used for joint exposure. Soft tissue release was started in the subperiosteal layer of the joint capsular insertion site on the proximal tibia and extended $1 \mathrm{~cm}$ distally and posteromedially. Subsequently, without further release, femoral and tibial articular surface resection was carried out and ligament balance was assessed using a trial prosthesis. Taking care to achieve symmetrical medial-lateral tension with the use of a prosthesis that is one size smaller than the trial one, an osteotome was inserted perpendicular to the resected articular surface for bone tissue removal in the proximal medial tibia. The bone resection was performed in $2 \mathrm{~mm}$ increments according to the level of the medial soft tissue contracture until a perfect ligament balance was confirmed with the insertion of the trial prosthesis.

Comparisons between the groups were based on the total operation (OP) time, ROM, HSS score, tibio-femoral mediallateral gap ratio examined with the knee in $0^{\circ}, 90^{\circ}$, and $130^{\circ}$ flexion under an image intensifier at 6 months postoperatively.

Total OP time starting from the initial skin incision to skin closure was measured. On the assessment of ROM at postoperative 6 months, the difference in the angle created by the femoral longitudinal axis and the tibial longitudinal axis with the knee in maximum flexion and extension on lateral radiographs was recorded.

To assess the tibio-femoral medial-lateral gap ratio at postoperative 6 months, the patient was placed in the supine position with the knee in $0^{\circ}, 90^{\circ}$, and $130^{\circ}$ flexion under an image magnifier that was set up to produce a cross-sectional image of the tibial articular surface on the AP view. The medial and lateral tibio-femoral gaps were measured with the knee in $0^{\circ}, 90^{\circ}$, and $130^{\circ}$ flexion on the picture archiving and communication system (PACS) and the lateral value was divided by the medial value to obtain the ratio at each flexion angle (Fig. 3).

Statistical analysis was performed using SPSS ver. 15.0 (SPSS Inc., Chicago, IL, USA) in order to analyze total OP time, ROM, HSS score, and tibio-femoral medial-lateral gap ratio at postoperative 6 months. The Mann-Whitney test was conducted to compare differences between the groups with a $95 \%$ confidence interval. 
Table 1. Clinical Raw Data for Total Knee Arthroplasty Cases with Mechanical Varus Deformity More Than $10^{\circ}$

\begin{tabular}{|c|c|c|c|c|c|c|c|c|c|c|c|}
\hline \multirow{2}{*}{ No. } & \multirow{2}{*}{ Age (yr) } & \multirow{2}{*}{$\begin{array}{l}\text { Osteotomy/ } \\
\text { release }\end{array}$} & \multirow{2}{*}{$\operatorname{Varus}\left({ }^{\circ}\right)$} & \multirow{2}{*}{$\begin{array}{l}\text { Operation } \\
\text { time (min) }\end{array}$} & \multicolumn{2}{|c|}{ Postoperative } & \multicolumn{3}{|c|}{ Medial-lateral ratio } & \multicolumn{2}{|c|}{ Preoperative } \\
\hline & & & & & ROM & HSS & $0^{\circ}$ & $90^{\circ}$ & $130^{\circ}$ & ROM & HSS \\
\hline 1 & 69 & Osteotomy & 13 & 100 & 135 & 93 & 1 & 1 & 1 & 135 & 65 \\
\hline 3 & 72 & Osteotomy & 15 & 99 & 140 & 90 & 1.1 & 1.1 & 1 & 135 & 62 \\
\hline 4 & 67 & Osteotomy & 13 & 85 & 130 & 91 & 1 & 1 & 1 & 130 & 60 \\
\hline 6 & 69 & Osteotomy & 14 & 101 & 133 & 98 & 1 & 1 & 1.1 & 130 & 65 \\
\hline 7 & 68 & Osteotomy & 15 & 89 & 132 & 96 & 1 & 1.1 & 1 & 130 & 57 \\
\hline 8 & 66 & Osteotomy & 12 & 90 & 136 & 94 & 1 & 1 & 1 & 125 & 63 \\
\hline 9 & 72 & Osteotomy & 14 & 105 & 132 & 92 & 1 & 1 & 1 & 135 & 68 \\
\hline 13 & 69 & Osteotomy & 15 & 97 & 142 & 90 & 1 & 1 & 1 & 135 & 68 \\
\hline 14 & 70 & Osteotomy & 12 & 95 & 136 & 94 & 1 & 1 & 1 & 130 & 70 \\
\hline 15 & 81 & Osteotomy & 11 & 105 & 135 & 96 & 1 & 1 & 1 & 125 & 62 \\
\hline 16 & 82 & Osteotomy & 13 & 89 & 132 & 96 & 1 & 1 & 1 & 130 & 57 \\
\hline 17 & 77 & Osteotomy & 19 & 85 & 133 & 92 & 1 & 1 & 1 & 135 & 66 \\
\hline 18 & 65 & Osteotomy & 11 & 105 & 131 & 94 & 1 & 1 & 1 & 125 & 57 \\
\hline 19 & 64 & Osteotomy & 13 & 110 & 138 & 92 & 1 & 1 & 1 & 130 & 61 \\
\hline 20 & 62 & Osteotomy & 17 & 90 & 138 & 90 & 1 & 1 & 1 & 85 & 64 \\
\hline 21 & 83 & Release & 13 & 115 & 140 & 92 & 1 & 1 & 1.2 & 135 & 56 \\
\hline 27 & 73 & Release & 11 & 112 & 130 & 90 & 1 & 1 & 1.2 & 120 & 69 \\
\hline 28 & 74 & Release & 17 & 118 & 142 & 96 & 1 & 1 & 1 & 135 & 63 \\
\hline 29 & 77 & Release & 16 & 125 & 140 & 94 & 1 & 1 & 1.2 & 90 & 59 \\
\hline 30 & 64 & Release & 11 & 118 & 133 & 92 & 1 & 1 & 1 & 125 & 64 \\
\hline 31 & 65 & Release & 15 & 110 & 135 & 92 & 1 & 1 & 1.1 & 130 & 70 \\
\hline 32 & 66 & Release & 12 & 118 & 136 & 90 & 1 & 1.1 & 1.2 & 130 & 71 \\
\hline 33 & 73 & Release & 11 & 110 & 137 & 94 & 1 & 1 & 1.1 & 125 & 63 \\
\hline 34 & 70 & Release & 15 & 109 & 138 & 92 & 1 & 1 & 1.2 & 135 & 68 \\
\hline 35 & 81 & Release & 14 & 110 & 136 & 90 & 1 & 1 & 1.1 & 130 & 65 \\
\hline 36 & 82 & Release & 15 & 121 & 137 & 92 & 1 & 1 & 1.2 & 135 & 57 \\
\hline 37 & 69 & Release & 14 & 118 & 138 & 94 & 1 & 1.1 & 1.2 & 90 & 61 \\
\hline 38 & 63 & Release & 11 & 123 & 132 & 96 & 1 & 1 & 1.1 & 125 & 64 \\
\hline 39 & 71 & Release & 12 & 121 & 130 & 92 & 1 & 1 & 1 & 120 & 63 \\
\hline 40 & 77 & Release & 13 & 119 & 135 & 90 & 1 & 1 & 1.2 & 125 & 66 \\
\hline
\end{tabular}

ROM: range of motion, HSS: hospital for special surgery. 


\section{Results}

Statistically significant intergroup differences were found in the total OP time and the tibio-femoral medial-lateral gap ratio in $130^{\circ}$ flexion. There was no significant difference in the preoperative HSS score and tibio-femoral angle on the whole leg standing AP view and postoperative ROM, HSS score, and tibiofemoral medial-lateral gap ratio in $0^{\circ}$ and $90^{\circ}$ flexion. The mean total OP time was remarkably short in the vertical osteotomy group (mean, 96.9 minutes; range, 80 to 119 minutes) compared to that in the medial release group (mean, 116.2 minutes; range, 109 to 125 minutes) ( $\mathrm{p}=0.000$ ). The mean tibio-femoral mediallateral gap ratio in $130^{\circ}$ flexion at postoperative 6 months was notably smaller in the vertical osteotomy group (1.02) than in the medial release group $(1.14 ; \mathrm{p}=0.000)$. However, the ratio was not significantly different between the groups in $0^{\circ}$ and $90^{\circ}$ flexion.

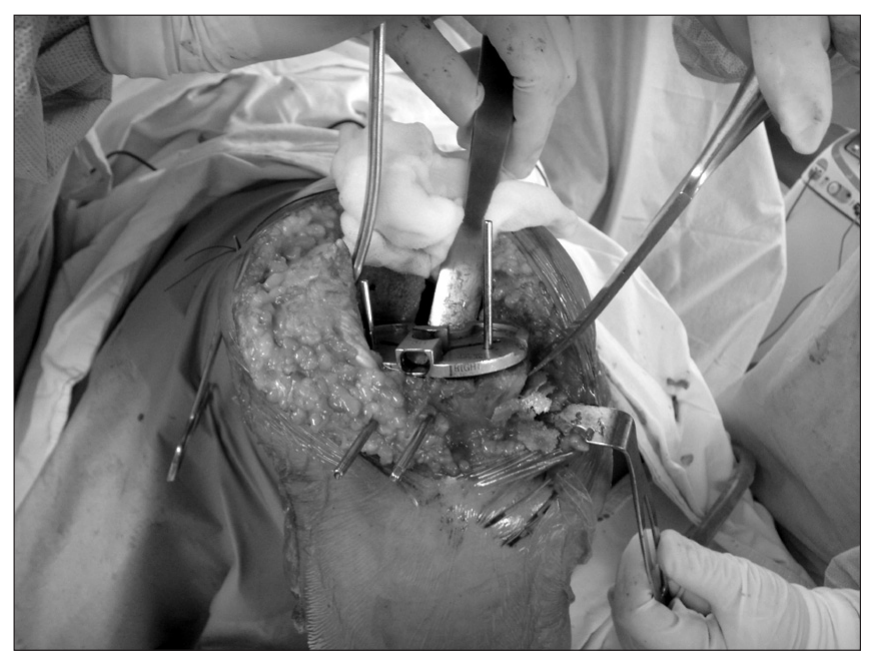

Fig. 2. Intraoperative photograph showing bony resection of proximal medial tibia using an osteotome for ligament balancing.
No significant intergroup difference was found in the ROM and HSS score at postoperative 6 months (Table 2).

In the vertical osteotomy group, the tibial component size was determined after bone resection by assessing the medial-lateral tension with a trial prosthesis. In this group, the final prosthesis of choice was one size smaller than the one selected before bone resection, which did not result in a size mismatch with the femoral component. In the medial release group, there were 2 cases of intraoperative partial MCL tear, which did not lead to any clinical problems after staple fixation (Fig. 4).

\section{Discussion}

There is a variety of surgical techniques for the treatment of degenerative arthritis of the knee according to the severity and extent of a lesion. Of these, TKA is the most common surgical intervention for profound degenerative arthritis in senior patients. Ligament balance is essential to the success of TKA and imbalance has been recognized as one of the major causes of early failure of TKA as well as pain during ambulation ${ }^{5,699}$. Sequential medial soft tissue release has been widely performed in varus arthritic knees ${ }^{10)}$, however, profound varus deformity often necessitates additional soft tissue release in the MCL and joint capsule $^{11,12)}$. An extensive medial soft tissue release performed in severe varus knees may result in overcorrection, for which a thick polyethylene insert or a constrained prosthesis should be used when a patient undergoes TKA ${ }^{13)}$. The conventional ligament balancing procedure involves removal of degenerative osteophytes and release of the contracted medial soft tissue at the tibial attachment site to obtain symmetrical medial-lateral tension in extension and $90^{\circ}$ flexion of the knee $\mathrm{e}^{1,3,14}$. This technique is advantageous in that various medial soft tissues, including the superficial and deep layers of the MCL, can be selectively released
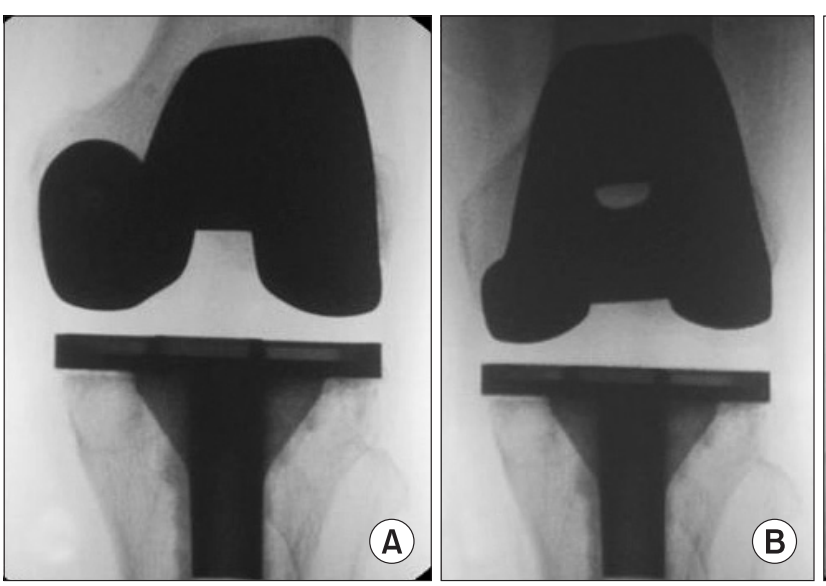

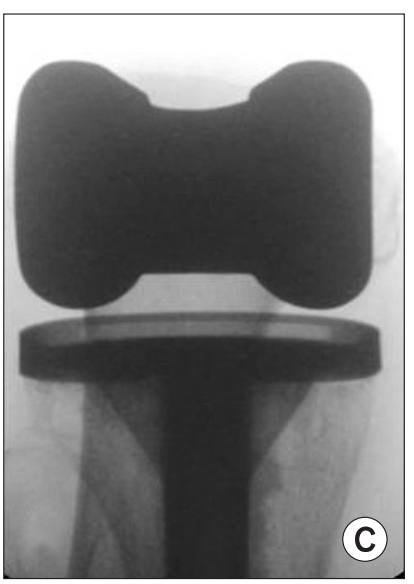

Fig. 3. Anteroposterior radiographs by an X-ray image intensifier showing tibiofemoral medial-lateral gap ratio changes according to different flexion angles at postoperative 6 months. (A) $0^{\circ}$ flexion. (B) $90^{\circ}$ flexion. (C) $130^{\circ}$ flexion. 
Table 2. Comparison between Vertical Osteotomy Group and Medial Release Group

\begin{tabular}{|c|c|c|}
\hline Group & Mean \pm SD (range) & $\mathrm{p}$-value \\
\hline Age (yr) & & 0.222 \\
\hline Osteotomy & $70.6 \pm 5.12(62-82)$ & \\
\hline Release & $72.5 \pm 5.77(63-83)$ & \\
\hline $\operatorname{Varus}\left({ }^{\circ}\right)$ & & 0.978 \\
\hline Osteotomy & $13.25 \pm 2.15(11-19)$ & \\
\hline Release & $13.25 \pm 2.17(11-18)$ & \\
\hline Operation time (min) & & 0.000 \\
\hline Osteotomy & $96.85 \pm 9.44(80-119)$ & \\
\hline Release & $116.20 \pm 5.39(109-125)$ & \\
\hline Postoperative ROM & & 0.376 \\
\hline Osteotomy & $134.45 \pm 3.58(128-142)$ & \\
\hline Release & $135.40 \pm 3.28(130-142)$ & \\
\hline Postoperative HSS & & 0.718 \\
\hline Osteotomy & $92.90 \pm 2.65(88-98)$ & \\
\hline Release & $92.60 \pm 2.06(90-96)$ & \\
\hline Medial-lateral ratio $\left(0^{\circ}\right)$ & & 0.553 \\
\hline Osteotomy & $1.01 \pm 0.03(1.0-1.1)$ & \\
\hline Release & $1.01 \pm 0.02(1.0-1.1)$ & \\
\hline Medial-lateral ratio $\left(90^{\circ}\right)$ & & 0.938 \\
\hline Osteotomy & $1.02 \pm 0.04(1.0-1.1)$ & \\
\hline Release & $1.03 \pm 0.06(1.0-1.2)$ & \\
\hline Medial-lateral ratio $\left(130^{\circ}\right)$ & & 0.000 \\
\hline Osteotomy & $1.02 \pm 0.04(1.0-1.1)$ & \\
\hline Release & $1.14 \pm 0.07(1.0-1.2)$ & \\
\hline Preoperative ROM & & 0.567 \\
\hline Osteotomy & $123.75 \pm 15.21(85-135)$ & \\
\hline Release & $124.25 \pm 12.59(90-135)$ & \\
\hline Preoperative HSS & & 0.212 \\
\hline Osteotomy & $63.00 \pm 4.58(55-72)$ & \\
\hline Release & $64.65 \pm 4.21(56-71)$ & \\
\hline
\end{tabular}

SD: standard derviation, ROM: range of motion, HSS: hospital for special surgery.

to adjust medial tension in extension and $90^{\circ}$ flexion of the $k^{2} e^{5,7}$. However, it is difficult to avoid medial soft tissue rupture during the procedure. To overcome this disadvantage, Dixon et al. ${ }^{8)}$ suggested longitudinal resection of the proximal medial tibia. Their method minimizes soft tissue release to prevent medial soft tissue rupture and uses vertical resection of the proximal medial tibia for ligament balance. Hence, it is expected to be more effective and safer than the conventional procedure, allowing minimal release of the superficial layer of the MCL in the tibial
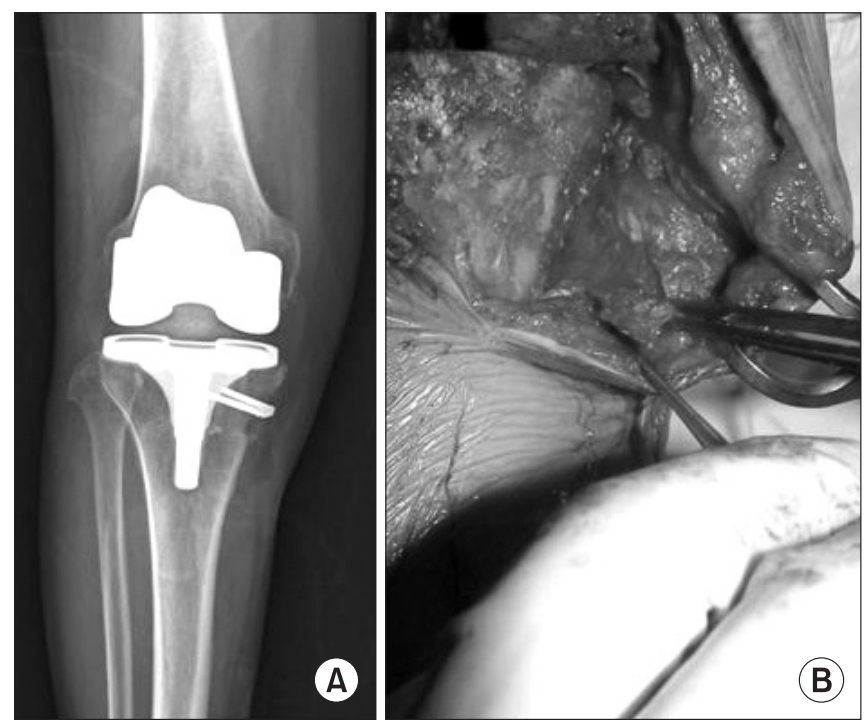

Fig. 4. (A) Anteroposterior radiograph of the right knee showing repair by staple for torn medial collateral ligament. (B) Intraoperative photograph showing torn medial collateral ligament during medial release.

attachment site ${ }^{8,15)}$. In this study, we compared the 2 ligament balancing techniques based on the total OP time, preoperative and 6-month postoperative ROM and HSS score, and tibiofemoral medial-lateral gap ratio in $0^{\circ}, 90^{\circ}$, and $130^{\circ}$ flexion. There were statistically significant differences in the total OP time and the ratio in $130^{\circ}$ knee flexion. The mean total OP time was longer in the medial release group than in the vertical osteotomy group. We attributed this to the use of a sequential release procedure to prevent excessive soft tissue release according to recommendations and technical difficulties caused by adhesion and contracture of medial soft tissues in knees with degenerative arthritis ${ }^{4,15}$. The mean total OP time in the medial release group could have been lengthened due to staple fixation in 2 cases with a partial rupture of the superficial layer of the MCL. The 2 cases were not excluded from the analysis under the assumption that the ruptures represented the risk of medial soft tissue release. The significantly lower tibio-femoral medial-lateral gap ratio in $130^{\circ}$ flexion in the vertical osteotomy group could be attributable to the lack of an aggressive medial release to avoid the possibility of medial soft tissue instability ${ }^{16)}$. The difference in the ratio in $130^{\circ}$ knee flexion did not result in significant intergroup difference in ROM. In spite of this, the results are worth consideration in TKA for Asian patients, because hyperflexion of the knee is often necessary in Asian culture ${ }^{17,18)}$.

Proximal medial tibial resection can be an effective method for ligament balancing. However, an extensive bone resection may cause tibial component loosening, difficulty in revision surgery, 
and kinematic changes in the knee due to lateral translation of the tibial component. Although extensive medial soft tissue release has been associated with knee instability in some studies, Choi et al. ${ }^{2}$ suggested that proper postoperative fixation could improve stability in knees with varus deformity even after extensive release of medial soft tissues including the MCL.

One of the limitations of this study is the 6-month short-term follow-up period in comparison to other studies. Although TKAs were bilateral in 13 of the 27 patients, the influence of personal differences on the postoperative ROM and HSS score were not taken into consideration in the analysis. In addition, the mediallateral gap was measured without weight bearing and thus the results may not reflect the possibility of instability during walking or daily living activities. The difference in the tibio-femoral medial-lateral gap ratio in $130^{\circ}$ flexion might have originated from the difference in the axis of knee flexion. Furthermore, the results could have been affected by the surgeon's preference or skills considering that all the operations were performed by the same surgeon in this study.

\section{Conclusions}

The 6-month short-term follow-up results of TKA showed that proximal medial tibial resection in severe varus knees can be effective in reducing operation time and achieving ligament balance in high flexion. We believe possible complications related to the procedure should be investigated in future long-term follow-up studies.

\section{Conflict of Interest}

No potential conflict of interest relevant to this article was reported.

\section{References}

1. Mullaji AB, Padmanabhan V, Jindal G. Total knee arthroplasty for profound varus deformity: technique and radiological results in 173 knees with varus of more than 20 degrees. J Arthroplasty. 2005;20:550-61.

2. Choi CH, Kim JH, Chung HK, Kim JH. Clinical and radiological evaluation of detached MCL cases in medial release during TKA: MCL detached vs stable CR vs stable PS. J Korean Knee Soc. 2002;14:1-8.

3. Bottros J, Gad B, Krebs V, Barsoum WK. Gap balancing in total knee arthroplasty. J Arthroplasty. 2006;21(4 Suppl 1):11-5.
4. Yagishita K, Muneta T, Ikeda H. Step-by-step measurements of soft tissue balancing during total knee arthroplasty for patients with varus knees. J Arthroplasty. 2003;18:313-20.

5. Kim JH, Choi CH, Kang SK, Lee BK, Shon KH, Chung HK. Assessment of failure modes in total knee replacement arthroplasty. J Korean Knee Soc. 2003;15:177-84.

6. Lee CC, Cho SD, Ko SH, Jang KH, Gwak CY, Jeong JY. Instability after total knee arthroplasty. J Korean Knee Soc. 2006;18:175-81.

7. Sim JA, Kwak JH, Yang SH, Kim JY, Lee BK. Short-term follow-up results of medial epicondylar osteotomy for the varus knee in TKA. J Korean Knee Soc. 2009;21:197-204.

8. Dixon MC, Parsch D, Brown RR, Scott RD. The correction of severe varus deformity in total knee arthroplasty by tibial component downsizing and resection of uncapped proximal medial bone. J Arthroplasty. 2004;19:19-22.

9. Insall JN, Binazzi R, Soudry M, Mestriner LA. Total knee arthroplasty. Clin Orthop Relat Res. 1985;(192):13-22.

10. Laskin RS, Schob CJ. Medial capsular recession for severe varus deformities. J Arthroplasty. 1987;2:313-6.

11. Teeny SM, Krackow KA, Hungerford DS, Jones M. Primary total knee arthroplasty in patients with severe varus deformity: a comparative study. Clin Orthop Relat Res. 1991;(273):19-31.

12. Vince KG, Abdeen A, Sugimori T. The unstable total knee arthroplasty: causes and cures. J Arthroplasty. 2006;21(4 Suppl 1):44-9.

13. Matsueda M, Gengerke TR, Murphy M, Lew WD, Gustilo RB. Soft tissue release in total knee arthroplasty: cadaver study using knees without deformities. Clin Orthop Relat Res. 1999;(366):264-73.

14. Whiteside LA. Soft tissue balancing: the knee. J Arthroplasty. 2002;17(4 Suppl 1):23-7.

15. McPherson EJ, Portugal D. Revision total knee arthroplasty for excessive ligamentotaxis. J Arthroplasty. 2007;22:1214-6.

16. Stahelin T, Kessler O, Pfirrmann C, Jacob HA, Romero J. Fluoroscopically assisted stress radiography for varus-valgus stability assessment in flexion after total knee arthroplasty. J Arthroplasty. 2003;18:513-5.

17. Sugama R, Kadoya Y, Kobayashi A, Takaoka K. Preparation of the flexion gap affects the extension gap in total knee arthroplasty. J Arthroplasty. 2005;20:602-7.

18. Yasgur DJ, Scuderi GR, Insall JN. Medial release for fixed varus deformity. In: Scuderi GR, Tria AJ, eds. Surgical technique in total knee arthroplasty. New York: Springer; 2002. p189-96. 